\title{
Approaches to Refractory Hypoxemia in Acute Respiratory Distress Syndrome: Current Understanding, Evidence, and Debate
}

\author{
Stephen R Collins MD and Randal S Blank MD PhD
}

\author{
Introduction \\ Lung-Recruitment Maneuvers \\ Airway Pressure-Release Ventilation \\ High-Frequency Ventilation \\ Prone Positioning \\ Inhaled Vasodilators: Nitric Oxide and Prostacyclin \\ Extracorporeal Membrane Oxygenation \\ Summary
}

\begin{abstract}
Acute lung injury (ALI) and acute respiratory distress syndrome (ARDS) cause substantial morbidity and mortality despite our improved understanding of lung injury, advancements in the application of lung-protective ventilation, and strategies to prevent ventilator-induced lung injury. Severe refractory hypoxemia may develop in a subset of patients with severe ARDS. We review several approaches referred to as "rescue" therapies for severe hypoxemia, including lung-recruitment maneuvers, ventilation modes, prone positioning, inhaled vasodilator therapy, and the use of extracorporeal membrane oxygenation. Each shows evidence for improving oxygenation, though each has associated risks, and no single therapy has proven superior in the management of severe hypoxemia. Importantly, increased survival with these strategies has not been clearly established. Key words: acute lung injury; ALI; acute respiratory distress syndrome; ARDS; refractory hypoxemia; recruitment maneuvers; airway pressure release ventilation; APRV; high-frequency oscillatory ventilation; HFOV; prone positioning; inhaled vasodilators; extracorporeal membrane oxygenation. [Respir Care 2011;56(10):1573-1582. () 2011 Daedalus Enterprises]
\end{abstract}

\section{Introduction}

The definitions of acute lung injury (ALI) and acute respiratory distress syndrome (ARDS) were standardized

\footnotetext{
Drs Collins and Blank are affiliated with the Department of Anesthesiology, University of Virginia School of Medicine, Charlottesville, Virginia.

On behalf of the authors, Charles G Durbin Jr MD FAARC, Department of Anesthesiology, University of Virginia, Charlottesville, Virginia, presented a version of this paper at the 26th New Horizons Symposium, "ARDS Update," at the 56th International Respiratory Congress of the American Association for Respiratory Care, held December 6-9, 2010, in Las Vegas, Nevada.
}

nearly 20 years ago at the American-European Consensus Conference $^{1}$ on the basis of clinical features that formed the basis for related investigations. The definitions are nearly identical (acute-onset of severe respiratory distress, bilateral alveolar infiltrates on chest radiograph, severe

\footnotetext{
The authors have disclosed no conflicts of interest.

Correspondence: Stephen R Collins MD, Department of Anesthesiology, University of Virginia School of Medicine, PO Box 800710, Charlottesville VA 22908. E-mail: src2f@virginia.edu.
}

DOI: $10.4187 /$ respcare. 01366 


\section{ApProaches to ReFRACTORY HyPOXEMIA IN ARDS}

hypoxemia, absence of left atrial hypertension, pulmonary capillary wedge pressure $\leq 18 \mathrm{~mm} \mathrm{Hg}$, and no clinical signs of left heart failure). ALI and ARDS differ only in the degree to which gas exchange is impaired, as measured by $\mathrm{P}_{\mathrm{aO}_{2}} / \mathrm{F}_{\mathrm{IO}_{2}}:$ ALI $\leq 300 \mathrm{~mm} \mathrm{Hg}$, ARDS $\leq 200 \mathrm{~mm} \mathrm{Hg}$. These definitions have important limitations because they do not distinguish the etiology of the lung injury, which can be either pulmonary (primary lung injury, such as pneumonia or inhalation injury) or extrapulmonary (multiple-organ insult, such as severe trauma or sepsis), and they do not account for differences in ventilatory management other than $\mathrm{F}_{\mathrm{IO}_{2}}$. Despite the pathophysiologic differences between primary and secondary lung injury, the outcomes are similar, at least as measured by intensive care unit (ICU) stay or hospital survival time. ${ }^{2}$ In fact, many studies regard ARDS of pulmonary or extrapulmonary origin as a single entity. Despite advances in our understanding of the mechanism and treatment of ALI and ARDS, the morbidity and mortality remain high. They affect up to 200,000 patients in the United States each year, with an in-hospital mortality rate of nearly $40 \%$. Mortality is as high as $60 \%$ in patients $\geq 85$ years old. ${ }^{3}$ Lung-protective ventilation strategies (tidal volume $\left[\mathrm{V}_{\mathrm{T}}\right]$ of $4-8 \mathrm{~mL} / \mathrm{kg}$ ideal body weight, plateau pressure $\leq 30 \mathrm{~cm} \mathrm{H}_{2} \mathrm{O}$, and modest PEEP) have a survival benefit. ${ }^{4}$ These methods have become the paradigm for lung-protection in ARDS patients and reduce mortality by nearly $25 \%$. By limiting excessive alveolar distention (volutrauma) caused by large $\mathrm{V}_{\mathrm{T}}$, lung injury from high pressure (barotrauma), and alveolar collapse (atelectrauma) caused by little or no PEEP, they minimize or avoid ventilator-induced lung injury and the associated cytokine-induced inflammatory response.

Patients who meet the American-European Consensus Conference criteria for ALI and ARDS supported by conventional lung-protection strategies may demonstrate improved oxygenation, shorter duration of ventilation, and lower ICU mortality. In one study, early application of an approach that included $\mathrm{V}_{\mathrm{T}}$ of $7-8 \mathrm{~mL} / \mathrm{kg}$, PEEP of $10 \mathrm{~cm} \mathrm{H}_{2} \mathrm{O}$, and $\mathrm{F}_{\mathrm{IO}_{2}}$ of 1.0 increased $\mathrm{P}_{\mathrm{aO}} / \mathrm{F}_{\mathrm{IO}_{2}}$ in less than a half hour in some patients, such that they no longer met the ALI or ARDS criteria. This suggests a need for the introduction of standardized ventilation settings into an ALI/ARDS definition. Despite these strategies, however, lung injury persists or progresses in some patients, leading to worsening or refractory hypoxemia. The oxygenation index predicts poor outcome from lung injury in the neonatal and pediatric population, ${ }^{5}$ and its utility is also evidenced in adults with ARDS. ${ }^{6}$ Oxygenation index links the severity of hypoxemia $\left(\mathrm{P}_{\mathrm{aO}_{2}} / \mathrm{F}_{\mathrm{IO}_{2}}\right)$ and mean airway pressure to a single variable:

Oxygenation index $=\left(\mathrm{F}_{\mathrm{IO}_{2}} \times\right.$ mean airway pressure $\left.\times 100\right) / \mathrm{P}_{\mathrm{aO}_{2}}$
An oxygenation index $>30$ has been suggested as an indication for non-conventional ventilation modes. ${ }^{7} \mathrm{~A}$ high oxygenation index after the onset of ARDS is an independent risk factor for mortality. ${ }^{6,7}$

Because of the severe, sometimes refractory, hypoxemia that develops in a subset of patients with ARDS, different approaches have been trialed over the years to improve oxygenation in hopes of improving outcome and increasing survival. Mortality from ARDS is usually due to multi-organ failure, often from sepsis; however, 10 $15 \%$ of patients die of refractory hypoxemia. ${ }^{8} \mathrm{~A}$ recent review ${ }^{9}$ defined refractory hypoxemia as $\mathrm{P}_{\mathrm{aO}_{2}} / \mathrm{F}_{\mathrm{IO}_{2}}$ $<100 \mathrm{~mm} \mathrm{Hg}$, inability to keep plateau pressure below $30 \mathrm{~cm} \mathrm{H}_{2} \mathrm{O}$ despite a $\mathrm{V}_{\mathrm{T}}$ of $4 \mathrm{~mL} / \mathrm{kg}$ ideal body weight, development of barotrauma, and oxygenation index $>30$.

Ventilatory and non-ventilatory strategies that have been used as "rescue" therapies in patients with refractory hypoxemia include lung-recruitment maneuvers, airway pressure-release ventilation (APRV), high-frequency oscillatory ventilation (HFOV), prone positioning, inhaled vasodilators (nitric oxide, prostacyclin), and extracorporeal membrane oxygenation (ECMO). Two of these therapies were recently reviewed in this journal. ${ }^{10,11}$ The strategies reviewed below do improve oxygenation in patients with severe ARDS (refractory hypoxemia unresponsive to conventional lung-protective ventilation strategies), but none of them has been proven superior to the others in improving oxygenation in this patient subset. Moreover, none has been shown to improve survival. With the exception of inhaled vasodilators and ECMO, these therapies depend on the potential for alveolar recruitment. By decreasing shunt fraction and dead space and improving lung compliance at a time when recruitment potential of damaged alveoli may be at its highest, better matched ventilation and perfusion is achieved.

This review discusses some of the common rescue therapies for ARDS refractory hypoxemia, the evidence supporting their use, and controversies about their roles. While any of these strategies may be considered, their use may be based on equipment availability, center-specific practice, or simply clinician bias. If required, the optimal time to initiate such therapies is thought to be within 96 hours of ARDS onset. Timely referral to a tertiary-care center with expertise in the management of these patients may be warranted.

\section{Lung-Recruitment Maneuvers}

Lung-recruitment maneuvers transiently increase transpulmonary pressure and open atelectatic alveoli, thus improving gas exchange. ${ }^{12-14}$ Lung-recruitment maneuvers include sustained high-pressure inflation, ${ }^{15}$ intermittent ${ }^{16}$ and extended sighs, ${ }^{17}$ intermittent PEEP increases, ${ }^{14}$ and pressure control with PEEP. ${ }^{18}$ No randomized controlled 


\section{ApProaches to ReFRACTORY HyPOXEMIA IN ARDS}

trials (RCTs) have shown a clear survival benefit from lung-recruitment maneuvers. In fact, despite the short-term oxygenation improvement, there is very little evidence of improved outcome. Nevertheless, transient physiologic improvements (namely, increased oxygenation and tissue perfusion) intuitively seem beneficial, and favorable secondary end points such as a lower rate of refractory hypoxemia in ARDS patients have been demonstrated. ${ }^{19}$

Patients with ARDS receiving lung-protective (low- $\mathrm{V}_{\mathrm{T}}$, low-pressure) ventilation may have a substantial proportion of collapsed lung tissue (perfused, non-ventilated alveoli). Recruiting these collapsed alveoli with high PEEP and other recruitment maneuvers is thought to improve oxygenation by reducing shunt. This concept was demonstrated in an animal model of ARDS in 1992. ${ }^{20}$ The first RCT that incorporated recruitment maneuvers (sustained high-pressure inflation with a low-volume, low-pressure lung-protective ventilation strategy) proposed that improved oxygenation should improve outcomes..$^{21}$ Three subsequent RCTs ${ }^{19,22,23}$ studied high PEEP in patients with ALI and ARDS, in an attempt to find the optimal PEEP strategy in ALI/ARDS patients. But, despite those trials, the best method to select PEEP in patients with ALI/ARDS remains poorly defined. In the Lung Open Ventilation trial, ${ }^{19}$ PEEP was administered according to an oxygenation scale. In the Expiratory Pressure (Express) trial, ${ }^{22}$ PEEP selection was based on bedside assessment of lung mechanics. Despite the different PEEP selection criteria, however, the PEEP levels were similar in the 2 studies, and the higher-PEEP groups had higher $\mathrm{P}_{\mathrm{aO}} / \mathrm{F}_{\mathrm{IO}_{2}}$. The Lung Open Ventilation trial also found a lower rate of refractory hypoxemia, death with refractory hypoxemia, and use of rescue therapies in the higher-PEEP group. Those data may favor higher PEEP in the early phase of ALI/ARDS. However, no mortality benefit was found in those studies.

Interestingly, a recent study ${ }^{24}$ with 68 ALI/ARDS patients, which examined the percentage of potentially recruitable lung with different PEEP settings, found that the patients with more recruitable lung had poorer oxygenation, greater dead-space fraction, and a higher mortality rate. Gattinoni et $\mathrm{al}^{24}$ hypothesized that patients with a higher percentage of recruitable lung probably had more atelectasis, given their greater underlying disease severity. Based on the available evidence, they recommend setting PEEP at the highest level compatible with a plateau pressure of $28-30 \mathrm{~cm} \mathrm{H}_{2} \mathrm{O}$ and a $\mathrm{V}_{\mathrm{T}}$ of $6 \mathrm{~mL} / \mathrm{kg}$ predicted body weight.

Several RCTs ${ }^{25-27}$ have evaluated specific recruitment maneuvers in patients with ALI/ARDS and have consistently found improved oxygenation. This effect tends to be short-lived, however, with a rapid decline in oxygenation gains as soon as $15-20$ min after the maneuver. ${ }^{28}$ High PEEP after a recruitment maneuver may affect the sus- tainability. The most recent systematic review of recruitment maneuvers included over 40 studies, with over 1,100 patients, and found that oxygenation significantly improved after recruitment maneuvers, with few serious adverse events (barotrauma, arrhythmia, transient hypotension). ${ }^{28}$ Persistent severe adverse events such as pneumothorax were rare. Significantly improved oxygenation for at least 4 hours has also been found in several studies ${ }^{13,29}$ that used a decremental PEEP trial after a recruitment maneuver. It seems unclear, however, if that result is due to the PEEP titration strategy, the recruitment maneuver, or both. In addition, overall mortality was not different. Moreover, recruitment-maneuver selection, optimal pressure, duration, and frequency are not well established. Whether recruitment maneuvers that improve oxygenation reduce lung injury or impact patient outcome remains to be determined. They certainly may play a role in patients with refractory, life-threatening hypoxemia, but should be avoided in patients with hemodynamic instability and those at high risk for barotrauma.

\section{Airway Pressure-Release Ventilation}

APRV is a time-triggered, pressure-limited, time-cycled ventilation mode designed to permit the patient to breathe spontaneously while receiving a high level of continuous airway pressure, with brief, intermittent periods of pressure release. APRV's design features are well described in recent reviews. ${ }^{9,30}$ In a paralyzed or heavily sedated patient, APRV is analogous to pressure controlled inverseratio ventilation. However, APRV provides a prolonged inspiratory phase without the need for paralysis or heavy sedation, so spontaneous ventilation can be maintained. Theoretical concerns about APRV include the occurrence of intrinsic PEEP if time at low airway pressure is too brief, and the potential for large $\mathrm{V}_{\mathrm{T}}$ in the setting of large pleural-pressure swings, ${ }^{31}$ both of which may contribute to ventilator-induced lung injury. It is thought that improved oxygenation with APRV results from lung recruitment aided by the diaphragm contraction that occurs during spontaneous ventilation. This is supported by animal models of lung injury that used computed tomography, ${ }^{32}$ and by studies in patients with ARDS that used electro-impedance tomography. 33

In several crossover studies, ${ }^{34-39}$ improvements in physiologic end points with APRV have been consistently reported. Patients with ARDS on APRV had improved intrapulmonary shunt, dead space, and, thus, overall ventilation-perfusion matching and oxygenation. They also had shorter duration of ventilation and ICU stay. ${ }^{40}$ One of the more recent, and largest, RCTs of APRV ${ }^{41}$ terminated early for futility, after failure to recruit its targeted 80 subjects. In the recruited subjects, mortality was similar between the groups at 28 days and at one year. 

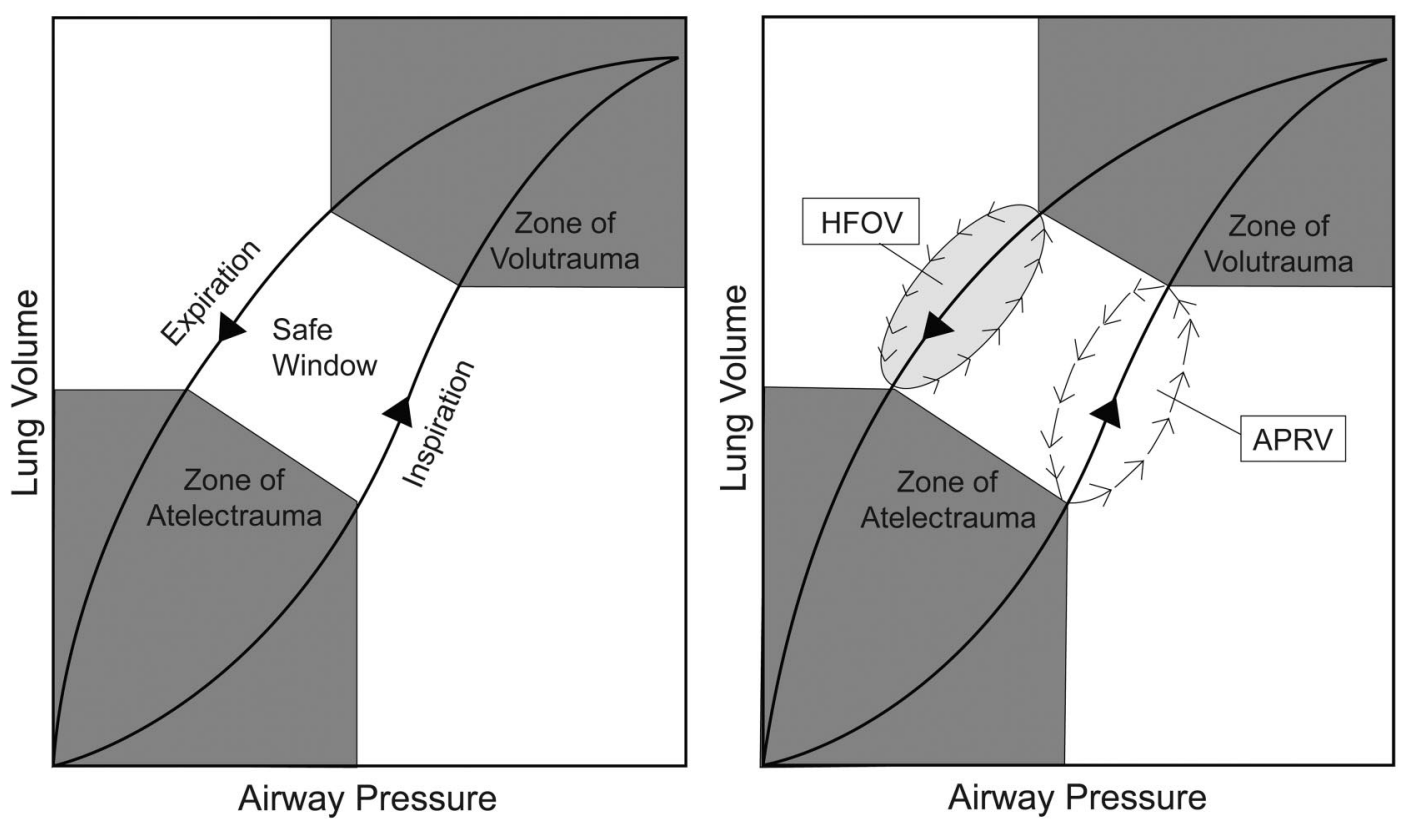

Fig. 1. Pressure-volume curves comparing ventilation regions with high-frequency oscillatory ventilation (HFOV) and airway pressurerelease ventilation (APRV). With HFOV ventilation occurs on the curve's expiratory limb, whereas with APRV ventilation occurs on the inspiratory limb. (From Reference 44, with permission.)

Most, though not all, studies on APRV have found improved oxygenation and hemodynamics, higher mean airway pressure that promoted alveoli recruitment, and a decreased need for sedation and/or paralytics. The clinical studies, however, have been few, small, and with confounding factors. For example, the aforementioned APRV trial involved just 58 patients, and both study arms used prone positioning, a technique known to improve oxygenation. Given the earlier-described concerns about APRV and the lack of evidence of a mortality benefit, additional trials are needed on APRV in ARDS patients.

\section{High-Frequency Ventilation}

High-frequency ventilation strategies can be broadly categorized as HFOV, high-frequency percussive ventilation, and high-frequency jet ventilation. These ventilation strategies employ very small $\mathrm{V}_{\mathrm{T}}$ and high respiratory rate, which permits higher end-expiratory lung volume and prevents overdistention while maintaining $\mathrm{P}_{\mathrm{aCO}_{2}}$. Whereas expiration is passive in high-frequency jet ventilation and high-frequency percussive ventilation, both inspiration and expiration are active processes with HFOV. Of the highfrequency ventilation strategies, HFOV is the most widely utilized in patients with ALI/ARDS and improves oxygenation in patients with refractory hypoxemia. Ventilation is achieved by the generation of extremely rapid pressure oscillations, usually in the range of 300-900 cycles/min, ${ }^{42}$ against an applied, relatively constant, airway pressure. Traditionally used with success in neonatology, HFOV is the most widely used form of high-frequency ventilation in adult critical care. ${ }^{43}$ The delivery of small $\mathrm{V}_{\mathrm{T}}$ and higher mean airway pressure improves alveolar recruitment with less end-expiratory collapse. Similar to APRV, HFOV can prevent barotrauma and atelectrauma; however, unlike APRV, it maintains patent alveoli on the deflation limb of the pressure-volume curve (Fig. 1). ${ }^{44}$ Disadvantages of HFOV include the risk of barotrauma, hemodynamic compromise, and the need for sedation and neuromuscular blockade to suppress spontaneous breathing activity and reduce patient-ventilator asynchrony. A new HFOV approach is a flow-demand system that facilitates spontaneous ventilation during the ventilatory cycle. ${ }^{45}$ Such modifications in HFOV technology may help to determine HFOV's benefits in ALI/ARDS as a rescue therapy.

Debate continues concerning the initiation and timing of HFOV in ALI/ARDS patients. In 2007 a round-table discussion $^{46}$ led to the recommendation of clinical thresholds for HFOV use. That group provided a systematic, logical approach to the use of HFOV, though they emphasized that early use of HFOV in ARDS patients cannot be recommended and no survival benefit has been shown. There is no validated, standardized algorithm for the use of HFOV, so its use remains institution-specific. Case reports ${ }^{47}$ and observational studies ${ }^{48}$ have found substantial oxygenation improvements in ARDS patients. Results have been sim- 
ilar with high-frequency percussive ventilation, though those studies were small and retrospective. ${ }^{49,50}$ There have been few RCTs with high-frequency ventilation in adults with ARDS. The largest, a multicenter trial ${ }^{51}$ in 13 United States hospitals, randomized 148 adults with ARDS to either HFOV or conventional ventilation $\left(\mathrm{V}_{\mathrm{T}} 6-10 \mathrm{~mL} / \mathrm{kg}\right.$ actual body weight, with initial PEEP $\geq 10 \mathrm{~cm} \mathrm{H}_{2} \mathrm{O}$ ). Thirty day mortality was $37 \%$ in the HFOV group and $52 \%$ in the conventional ventilation group $(P=.10)$ and that difference remained nonsignificant at 6 months. There were no significant differences in secondary outcomes. Of note, that trial was designed before the publication of the ARDS Network trial ${ }^{4}$ and thus before more well defined lung-protective ventilation strategies. Derdak et al found that HFOV was safe, not associated with adverse hemodynamic effects, and able to transiently (for $<24 \mathrm{~h}$ ) improve oxygenation.

The second largest RCT ${ }^{52}$ on HFOV was terminated prematurely after inclusion of 61 adult patients. Patients were randomized to HFOV or conventional ventilation with a $\mathrm{V}_{\mathrm{T}}$ of $8 \mathrm{~mL} / \mathrm{kg}$ predicted body weight. The trial had power to detect only major differences in outcome (survival), and no difference was found. An updated, more recent systematic review and meta-analysis ${ }^{53}$ included the latter $2 \mathrm{RCTs}^{51,52}$ and 6 smaller studies (two in children). The pooled results ( $>400$ patients) suggested that HFOV reduced 30 day mortality, compared to conventional mechanical ventilation, although that survival benefit was not significant in the individual studies of adults with ARDS. The analysis was limited by the small number and size of studies, and their heterogeneity. Larger, perhaps more definitive, trials ${ }^{54}$ hope to provide a clearer answer about mortality. Moreover, morbidity measures, including quality of life, will be assessed. At present, the data regarding the survival benefits of HFOV are inconclusive.

\section{Prone Positioning}

Prone positioning has gained support in recent years because of its ability to improve oxygenation in patients with ALI/ARDS. The physiologic benefits of prone positioning have been attributed to improved lung recruitment, ventilation-perfusion matching, and oxygenation. Improved ventilation-perfusion matching and gas exchange was the earliest rationale for prone positioning, ${ }^{55}$ and the technique has since become an adjunctive strategy to improve oxygenation in ARDS. Its use has been supported by animal studies, case series, RCTs, and systematic reviews, though questions remain as to the appropriate timing and duration of prone positioning. Prone positioning for more than 20 hours per day may be required for maximum benefit. Prone positioning should be abandoned if there is no oxygenation improvement after 24 hours. Patient response to prone positioning is variable, and factors that correspond to oxygenation improvement have not been well characterized. ${ }^{10}$ These include the cause of ARDS, the stage (early vs late), the patient's body habitus, and the severity of hypoxemia. Up to a third of patients show no physiologic improvement. A wide range exists for those who do respond, including a prolonged effect of improved oxygenation versus deterioration in $\mathrm{P}_{\mathrm{aO}_{2}} / \mathrm{F}_{\mathrm{IO}_{2}}$ when returned supine. ${ }^{56}$ This variability adds to the controversy over the broad application of a technique with uncertain benefit. Serious adverse events include pressure ulcers, facial edema, inadvertent extubation, and dislodgement of monitors and vascular catheters.

One of the earliest randomized controlled studies on prone positioning in respiratory failure found no survival benefit in a trial with 304 patients. ${ }^{57}$ The patients were kept prone continuously for at least 6 hours per day for 10 days. The study was underpowered, had substantial crossover between groups, and important confounders were not controlled. A subsequent study ${ }^{58}$ attempted to address such shortcomings but had additional problems with enrollment exclusions and failure to control mechanical ventilation strategies. Later RCTs improved on these deficiencies. For instance, one recent multicenter trial ${ }^{59}$ enrolled patients solely with ARDS (not ALI or milder lung injury), controlled for crossover between groups, and prone-positioned patients for a target of 20 hours each day, with a mean of 10 days. Though the differences were not significant, the results favored prone positioning in those patients. Methodological issues, however, prevent any firm conclusions from that study. It was stopped early due to patient enrollment, was underpowered, and did not control mechanical ventilation in the 2 groups. A more recent and larger trial ${ }^{60}$ with an improved design enrolled 344 patients and also targeted 20 hours per day in the pronepositioning group. It also standardized lung-protective ventilation between the groups $\left(\mathrm{V}_{\mathrm{T}}\right.$ of $8 \mathrm{~mL} / \mathrm{kg}$ ideal body weight with plateau pressure $<30 \mathrm{~cm} \mathrm{H}_{2} \mathrm{O}$ ). Gas exchange improved more quickly in the prone group; however, there was no significant difference in 28-day or 6-month mortality.

In 2008, 4 meta-analyses ${ }^{61-64}$ were published on prone positioning, and each found no mortality benefit. However, post hoc analysis supported prone positioning in certain subgroups. For example, in one of the most recent meta-analyses, ${ }^{65}$ prone positioning reduced mortality in the patients with the lowest $\mathrm{P}_{\mathrm{aO}_{2}} / \mathrm{F}_{\mathrm{IO}_{2}}(<100 \mathrm{~mm} \mathrm{Hg})$. Persistent improvement (for days) in $\mathrm{P}_{\mathrm{aO}} / \mathrm{F}_{\mathrm{IO}_{2}}$ was found, although with more complications, such as development of pressure ulcers, unplanned extubation, and loss of central venous access. In summary, prone positioning is not indicated as a routine strategy in ARDS but may be useful in patients with severe refractory hypoxemia. 


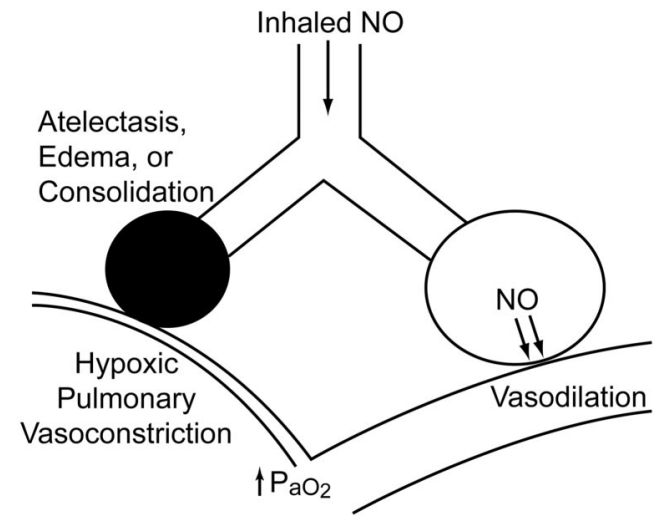

Fig. 2. Inhaled nitric oxide (NO) reaches only the ventilated alveoli and thus vasodilates only the ventilated pulmonary vessels, which improves ventilation-perfusion matching $(\dot{V} / \dot{Q})$.

\section{Inhaled Vasodilators: Nitric Oxide and Prostacyclin}

Inhaled vasodilators such as inhaled nitric oxide (INO) selectively vasodilate the pulmonary vasculature in ventilated alveoli (Fig. 2), which improves ventilation-perfusion matching and hypoxemia and lowers pulmonary arterial pressure. The short half-life of inhaled vasodilators minimizes systemic adverse effects, such as hypotension, that occur with systemic administration of pulmonary vasodilators. One characteristic of ARDS is pulmonary hypertension secondary to lung inflammation and thromboembolic occlusion of the pulmonary vasculature. ${ }^{66,67} \mathrm{By}$ lowering pulmonary arterial pressure, inhaled vasodilators may reduce the formation of pulmonary edema and reduce right-ventricle afterload. INO and aerosolized prostacyclin are the selective pulmonary vasodilators that have been most studied in ARDS patients, though they have been administered off-label in patients with ALI/ARDS. Both INO and aerosolized prostacyclin transiently improve oxygenation, but no study has shown improved survival or reduced duration of mechanical ventilation.

INO has an extremely short vasodilation half-life because it is rapidly inactivated by hemoglobin. INO is costly, requires specialized equipment, can induce methemoglobinemia (at an INO dose of $>40 \mathrm{ppm}$; dose range 2-80 ppm), and the accumulation of reactive nitrogen species such as nitrogen dioxide may have pro-inflammatory effects. A recent systematic review and meta-analysis ${ }^{68}$ found these adverse effects to be rare. Rebound pulmonary hypertension may also occur if INO is discontinued too quickly. INO's effect on oxygenation may be substantial, particularly at a low dose (peak oxygenation typically with INO dose $\leq 20 \mathrm{ppm}$ ). Some authors ${ }^{69}$ have suggested that, given INO's high cost, substantial oxygenation improvement should be exhibited within the first hour to warrant continued use.

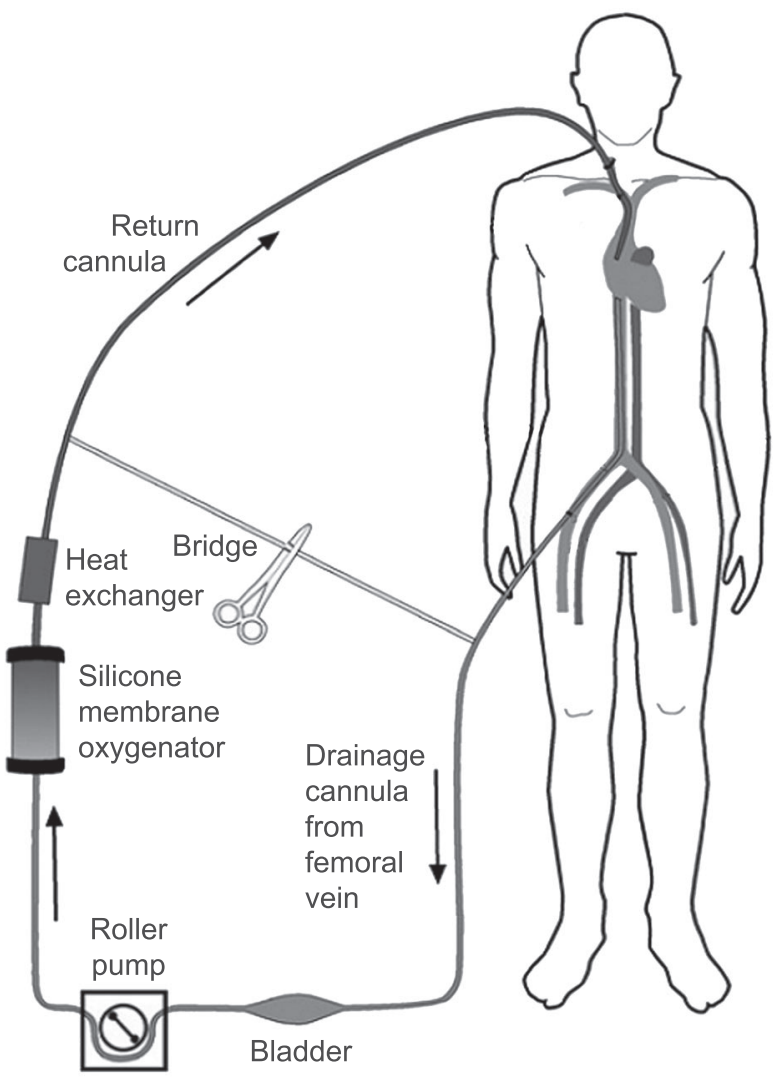

Fig. 3. Extracorporeal membrane oxygenation. Blood is removed at the femoral vein, pumped through a silicone membrane oxygenator and heat exchanger, and then returned to the right-heart circulation. (Adapted from Reference 76, with permission.)

Numerous RCTs $\mathrm{s}^{70-74}$ have explored the effect of INO in ARDS patients. Despite improved oxygenation (from 24 $96 \mathrm{~h}$ ), no survival benefit has been found. For instance, one of the early RCTs ${ }^{69}$ found a $60 \%$ response rate to INO $\left(\mathrm{P}_{\mathrm{aO}_{2}}\right.$ increase $\left.\geq 20 \%\right)$, compared to $24 \%$ in the placebo group. That $\mathrm{P}_{\mathrm{aO}_{2}}$ increase in the INO group allowed decreased ventilator settings over the next several days, as measured by the oxygenation index. However, the duration of mechanical ventilation and the mortality rate were unchanged. INO also significantly increases the risk of renal dysfunction, ${ }^{65}$ at least as found in a post hoc analysis of pooled trials. However, INO is used as a rescue therapy in patients with refractory hypoxemia and may be a shortterm adjunct to cardiopulmonary support in patients with life-threatening hypoxemia and severe pulmonary hypertension. ${ }^{75}$ It may be also be useful in combination with other rescue measures.

Prostacyclin has effects similar to those of INO, causing selective pulmonary vasodilation. Prostaglandin I-2 (epoprostenol) is one of the most studied prostacyclins. Our understanding of inhaled prostacyclins emerges mostly from studies in the treatment of pulmonary hypertension 
Table 1. Modalities to Treat Refractory Hypoxemia in Patients With Acute Respiratory Distress Syndrome

\begin{tabular}{|c|c|c|c|}
\hline Modality & Advantages & Disadvantages & Risks and Contraindications \\
\hline $\begin{array}{l}\text { Lung-recruitment } \\
\text { maneuvers }\end{array}$ & Well tolerated, generally safe & Improvements transient & $\begin{array}{l}\text { Contraindications: hemodynamic } \\
\text { instability } \\
\text { High risk of barotrauma }\end{array}$ \\
\hline $\begin{array}{l}\text { Airway pressure-release } \\
\text { ventilation }\end{array}$ & $\begin{array}{l}\text { Improved pulmonary mechanics, } \\
\text { gas exchange, hemodynamics, } \\
\text { less sedation }\end{array}$ & $\begin{array}{l}\text { Theoretical risk of large pleural } \\
\text { pressure swings }\end{array}$ & $\begin{array}{l}\text { Theoretical risk: large tidal volume } \\
\text { could increase risk of ventilator- } \\
\text { induced lung injury }\end{array}$ \\
\hline $\begin{array}{l}\text { High-frequency oscillatory } \\
\text { ventilation }\end{array}$ & May minimize atelectrauma & $\begin{array}{l}\text { Concern about higher inflammation } \\
\text { markers }\end{array}$ & Theoretical risk: lung inflammation \\
\hline Prone positioning & $\begin{array}{l}\text { Homogeneous distribution } \\
\text { of ventilation }\end{array}$ & Variable response, resource-intensive & $\begin{array}{l}\text { Risks: loss of airway, vascular } \\
\text { catheter, or chest drain; pressure } \\
\text { ulcers; cardiac arrest }\end{array}$ \\
\hline $\begin{array}{l}\text { Inhaled nitric oxide, } \\
\text { prostacyclin }\end{array}$ & $\begin{array}{l}\text { Reduces right-ventricular } \\
\text { afterload }\end{array}$ & Cost, delivery technologies & $\begin{array}{l}\text { Inhaled nitric oxide risks: renal } \\
\text { dysfunction, methemoglobinemia, } \\
\text { reactive nitrogen species, rebound } \\
\text { pulmonary hypertension }\end{array}$ \\
\hline $\begin{array}{l}\text { Extracorporeal membrane } \\
\text { oxygenation }\end{array}$ & $\begin{array}{l}\text { Can provide complete } \\
\text { ventilatory and } \\
\text { cardiovascular support }\end{array}$ & $\begin{array}{l}\text { Cost, resource utilization, limited } \\
\text { availability }\end{array}$ & $\begin{array}{l}\text { Risks: numerous, including bleeding, } \\
\text { infection, stroke } \\
\text { Contraindications: numerous }\end{array}$ \\
\hline
\end{tabular}

and right-heart failure. Inhaled prostaglandin I-2 is cheaper than INO, does not require a specialized delivery system, and has fewer potential adverse effects. The oxygenation improvement from inhaled prostacyclin is nearly identical to that of INO. ${ }^{11}$ Additional theoretical prostacyclin benefits include anti-inflammatory properties, thrombolytic effects, and inhibition of platelet aggregation. However, the safety profile of prostaglandin I-2 is not as well studied, there is no standardized delivery system, and there have been no important clinical outcome studies, so evidence is lacking that prostacyclin's known benefits produce meaningful outcome differences in patients with ALI or ARDS. Prostacyclin use remains controversial in ALI/ARDS.

\section{Extracorporeal Membrane Oxygenation}

ECMO is a technique that dissociates mechanical ventilation and gas exchange, thereby reducing ventilator-associated lung injury. Blood is removed from the patient at a high flow, pumped through an artificial lung, then returned to the patient (Fig. 3). ${ }^{76}$ ECMO can be either venovenous or venoarterial. Though ECMO's use is still controversial in adult respiratory failure, ECMO circumvents pulmonary gas exchange and has been suggested as the definitive therapy in the treatment of refractory, lifethreatening hypoxemia. ${ }^{66}$ However, ECMO has high cost and resource utilization. ECMO was first compared to conventional mechanical ventilation in adults with acute respiratory failure in 1979, and the mortality rate was greater than $90 \%$ in both arms. ${ }^{77}$ The next $\mathrm{RCT}^{78}$ of ECMO in respiratory failure was not reported until 1994, and it also found no survival difference. Neither study compared ECMO to a volume-limited, pressure limited ventilation strategy. Despite these earlier studies, benefits of ECMO described in several case series ${ }^{79,80}$ led to a recent RCT in the United Kingdom, which included 180 patients $^{81}$ and found that $63 \%$ of patients in the ECMO consideration group survived to 6 months without disability (only 68 of 90 patients randomized to receive ECMO actually did receive ECMO in an intention-to-treat analysis), compared to $47 \%$ of patients assigned to conventional management. However, those results are controversial; the criticisms include a lack of standardized treatment in the control group and referral of all ECMO-arm patients to one specialized referral center. The difficulty in reproducibility and other methodological shortcomings of the trial limit its usefulness in the debate on the role of ECMO for adults with ARDS.

Based on the above studies, the use of ECMO in ARDS and refractory hypoxemia remains controversial. Renewed interest was recently generated from a case series ${ }^{82}$ from Australia and New Zealand. ECMO was used in 61 patients with H1N1 influenza-associated ARDS, and their survival rate was $79 \%$. However, confounders in the study may include indication for ECMO use and underlying disease process. Given the expense, invasiveness, availability, and risks of ECMO, conclusive outcomes on survival benefit in ARDS are likely to remain elusive. Cost, resource availability, safety, and transport feasibility remain serious limitations to ECMO use in patients with ARDS.

Extracorporeal $\mathrm{CO}_{2}$ removal is an alteration of traditional ECMO, in which the circuit's pump is eliminated. Instead, the patient's native cardiac output serves as the pump in this modified ECMO circuit, also referred to as pumpless arteriovenous $\mathrm{CO}_{2}$ removal or pumpless extracorporeal lung assist. Gas exchange occurs via diffusion in 


\section{ApProaches to ReFRACTORY HyPOXEMIA IN ARDS}

a circuit membrane, and enables a more protective mechanical ventilation strategy. In contrast to ECMO, full extracorporeal oxygenation is not possible with extracorporeal $\mathrm{CO}_{2}$ removal; however, bleeding complications are reduced with elimination of the pump. ${ }^{83}$ One recently developed extracorporeal $\mathrm{CO}_{2}$ removal device is the Novalung (Novalung, Hechingen, Germany). ${ }^{84,85}$ The Novalung circuit diverts about $20 \%$ of the patient's cardiac output through the device, via the femoral artery, and reinfuses the blood into the femoral vein after $\mathrm{CO}_{2}$ removal, which is regulated by titrating the gas flow to the membrane. Device modifications include the addition of a pump, for higher flow. The primary indication of extracorporeal $\mathrm{CO}_{2}$ removal may be severe hypercarbia without hypoxemic respiratory failure. Successful application has been described in case reports of life-threatening asthma, ${ }^{86}$ as a bridge to lung transplantation, ${ }^{87}$ and in ARDS. ${ }^{88} \mathrm{~A}$ recent prospective study of 51 patients who met ARDS criteria and received early extracorporeal $\mathrm{CO}_{2}$ removal reported rapid arterial $\mathrm{CO}_{2}$ removal that allowed prompt reduction in $\mathrm{V}_{\mathrm{T}}$ and plateau pressure during mechanical ventilation. However, to date no survival benefit has been shown from extracorporeal $\mathrm{CO}_{2}$ removal in patients with ALI/ARDS.

\section{Summary}

Lung-protective ventilation with low $\mathrm{V}_{\mathrm{T}}$, low pressure, and high PEEP may offer a survival benefit in ARDS patients. A recent meta-analysis suggested a survival benefit from higher PEEP in patients with ARDS, whereas lower PEEP is more appropriate for ALI. ${ }^{89}$ All the rescue therapies described in this review improve oxygenation in patients with ARDS and severe hypoxemia, but none have demonstrated superiority, and no mortality benefit has been made evident. Their routine use is not recommended, given the lack of conclusive benefit, but each is appealing for sound physiological reasons, and all have been used in the treatment of severe ARDS with refractory hypoxemia (Table 1). Until well designed, adequately powered RCTs demonstrate their efficacy, these therapies should be considered for rescue only in patients with severe ARDS and refractory hypoxemia who have failed standard therapies. Choices between these rescue therapies are likely to be based upon clinician familiarity, resource availability, and cost considerations.

\section{REFERENCES}

1. Bernard G, Artigas A, Brigham K, Carlet J, Falke K, Hudson L, et al. The American-European Consensus Conference on ARDS. Definitions, mechanisms, relevant outcomes, and clinical trial coordination. Am J Respir Crit Care Med 1994;149(3 Pt 1):818-824.

2. Agarwal R, Aggarwal A, Gupta D, Behera D, Jindal S. Etiology and outcomes of pulmonary and extrapulmonary acute lung injury/ARDS in a respiratory ICU in North India. Chest 2006;130(3):724-729.
3. Rubenfeld G, Caldwell E, Peabody E, Weaver J, Martin D, Neff M, et al. Incidence and outcomes of acute lung injury. N Engl J Med 2005;353(16):1685-1693.

4. The Acute Respiratory Distress Syndrome Network. Ventilation with lower tidal volumes as compared with traditional tidal volumes for acute lung injury and the acute respiratory distress syndrome. N Engl J Med 2000;342(18):1301-1308.

5. Trachsel D, McCrindle B, Nakagawa S, Bohn D. Oxygenation index predicts outcome in children with acute hypoxemic respiratory failure. Am J Respir Crit Care Med 2005;172(2):206-211.

6. Seeley E, McAuley D, Eisner M, Miletin M, Matthay M, Kallet R. Predictors of mortality in acute lung injury during the era of lung protective ventilation. Thorax 2008;63(11):994-998.

7. Fort P, Farmer C, Westerman J, Johannigman J, Beninati W, Dolan S, et al. High-frequency oscillatory ventilation for adult respiratory distress syndrome: a pilot study. Crit Care Med 1997;25(6):937-947.

8. Stapleton R, Wang B, Hudson L, Rubenfeld G, Caldwell E, Steinberg K. Causes and timing of death in patients with ARDS. Chest 2005;128(2):525-532.

9. Esan A, Hess D, Raoof S, George L, Sessler C. Severe hypoxemic respiratory failure: part 1: ventilatory strategies. Chest 2010;137(5): 1203-1216.

10. Fessler H, Talmor D. Should prone positioning be routinely used for lung protection during mechanical ventilation? Respir Care 2010; 55(1):88-99.

11. Siobal M, Hess D. Are inhaled vasodilators useful in acute lung injury and acute respiratory distress syndrome? Respir Care 2010; 55(2):144-161

12. Grasso S, Mascia L, Del Turco M, Malacarne P, Giunta F, Brochard $\mathrm{L}$, et al. Effects of recruiting maneuvers in patients with acute respiratory distress syndrome ventilated with protective ventilatory strategy. Anesthesiology 2002;96(4):795-802.

13. Borges J, Okamoto V, Matos G, Caramez M, Arantes P, Barros F, et al. Reversibility of lung collapse and hypoxemia in early acute respiratory distress syndrome. Am J Respir Crit Care Med 2006;174(3): 268-278.

14. Foti G, Cereda M, Sparacino M, Marchi L, Villa F, Pesenti A. Effects of periodic lung recruitment maneuvers on gas exchange and respiratory mechanics in mechanically ventilated acute respiratory distress syndrome (ARDS) patients. Intensive Care Med 2000;26(5): 501-507.

15. Lapinsky S, Aubin M, Mehta S, Boiteau P, Slutski A. Safety and efficacy of a sustained inflation for alveolar recruitment in adults with respiratory failure. Intensive Care Med 1999;25(11):1297-1301.

16. Pelosi P, Cadringher P, Bottino N, Panigada M, Carrieri F, Riva E, et al. Sigh in acute respiratory distress syndrome. Am J Respir Crit Care Med 1999;159(3):872-880.

17. Lim C, Koh Y, Park W Chin J, Shim T, Lee S, et al. Mechanistic scheme and effect of 'extended sigh' as a recruitment maneuver in patients with acute respiratory distress syndrome: a preliminary study. Crit Care Med 2001;29(6):1255-1260.

18. Medoff B, Harris R, Kesselman H, Venegas J, Amato M, Hess D. Use of recruitment maneuvers and high-positive end-expiratory pressure in a patient with acute respiratory distress syndrome. Crit Care Med 2000;28(4):1210-1216.

19. Meade M, Cook D, Guyatt G, Slutsky A, Arabi Y, Cooper J. Lung Open Ventilation Study Investigators. Ventilation strategy using low tidal volumes, recruitment maneuvers, and high positive end-expiratory pressure for acute lung injury and acute respiratory distress syndrome: a randomized controlled trial. JAMA 2008;299(6):637645.

20. Lichtwarck-Aschoff M, Nielsen J, Sjöstrand U, Edgren E. An experimental randomized study of five different ventilator modes in a 


\section{APPROACHES to ReFRACTORY HyPOXEMIA IN ARDS}

piglet model of severe respiratory distress. Intensive Care Med 1992; 18(6):339-347.

21. Amato M, Barbas C, Medeiros D, Magaldi R, Schettino G, LorenziFilho G, et al. Effect of a protective-ventilation strategy on mortality in the acute respiratory distress syndrome. N Engl J Med 1998; 338(6):347-354

22. Mercat A, Richard J, Vielle B, Jaber S, Osman D, Diehl J, et al; Expiratory Pressure (Express) Study Group. Positive end-expiratory pressure setting in adults with acute lung injury and acute respiratory distress syndrome: a randomized controlled trial. JAMA 2008;299(6): 646-655.

23. National Heart, Lung, and Blood Institute ARDS Clinical Trials Network. Higher versus lower positive end-expiratory pressures in patients with the acute respiratory distress syndrome. N Engl J Med 2004;351(4):327-336.

24. Gattinoni L, Caironi P, Cressoni M, Chiumello D, Ranieri V, Quintel $\mathrm{M}$, et al. Lung recruitment in patients with the acute respiratory distress syndrome. N Engl J Med 2006;354(17):1775-1786.

25. ARDS Clinical Trials Network; National Heart, Lung, and Blood Institute; National Institutes of Health. Effects of recruitment maneuvers in patients with acute lung injury and acute respiratory distress syndrome ventilated with high positive end-expiratory pressure. Crit Care Med 2003;31(11):2592-2597.

26. Meade M, Cook D, Griffith L, Hand L, Lapinski S, Steward T, et al. A study of the physiologic responses to a lung recruitment maneuver in acute lung injury and acute respiratory distress syndrome. Respir Care 2008;53(11):1441-1449.

27. Oczenski W, Hörmann C, Keller C, Lorenzl N, Kepka A, Schwarz S, et al. Recruitment maneuvers after a positive end-expiratory pressure trial do not induce sustained effects in early adult respiratory distress syndrome. Anesthesiology 2004;101(3):620-625.

28. Fan E, Wilcox M, Brower R, Stewart T, Mehta S, Lapinsky S, et al. Recruitment maneuvers for acute lung injury: a systematic review. Am J Respir Crit Care Med 2008;178(11):1156-1163.

29. Girgis K, Hamed H, Khater Y, Kacmarek R. A decremental PEEP trial identifies the PEEP level that maintains oxygenation after lung recruitment. Respir Care 2006;51(10):1132-1139.

30. Liu L, Aldrich M, Shimabukuro D, Sullivan K, Taylor J, Thornton $\mathrm{K}$, et al. Rescue therapies for acute hypoxemic respiratory failure. Anesth Analg 2010;111(3):693-702.

31. Neumann P, Golisch W, Strohmeyer A, Buscher H, Burchardi H, Sydow M. Influence of different release times on spontaneous breathing pattern during airway pressure release ventilation. Intensive Care Med 2002;28(12):1742-1749.

32. Wrigge H, Zinserling J, Neumann P, Defosse J, Magnusson A, Putensen $\mathrm{C}$, et al. Spontaneous breathing improves lung aeration in oleic acid-induced lung injury. Anesthesiology 2003;99(2):376-384.

33. Putensen C, Wrigge $\mathrm{H}$. Clinical review: biphasic positive airway pressure and airway pressure release ventilation. Crit Care 2004; 8(6):492-497.

34. Sydow M, Burchardi H, Ephraim E, Zielmann S, Crozier T. Longterm effects of two different ventilator modes on oxygenation in acute lung injury. Comparison of airway pressure release ventilation and volume-controlled inverse ratio ventilation. Am J Respir Crit Care Med 1994;149(6):1550-1556.

35. Kaplan L, Bailey H, Formosa V. Airway pressure release ventilation increased cardiac performance in patients with acute lung injury/ adult respiratory distress syndrome. Crit Care 2001;5(4):221-226.

36. Räsänen J, Cane R, Downs J, Hurst J, Jousela I, Kirby, et al. Airway pressure release ventilation during acute lung injury: a prospective multicenter trial. Crit Care Med 1991;19(10):1234-1241.

37. Cane R, Peruzzi W, Shapiro B. Airway pressure release ventilation in severe acute respiratory failure. Chest 1991;100(2):460-463.
38. Dart B, Maxwell R, Richart C, Brooks D, Ciraulo D, Barker D, et al. Preliminary experience with airway pressure release ventilation in a trauma/surgical intensive care unit. J Trauma 2005;59(1):71-76.

39. Schultz T, Costarino A, Durning S, Napoli L, Schears G, Godinez R, et al. Airway pressure release ventilation in pediatrics. Pediatr Crit Care Med 2001;2(3):243-246.

40. Putensen C, Zech S, Wrigge H, Zinserling J, Stuber F, von Spiegel $\mathrm{T}$, et al. Long-term effects of spontaneous breathing during ventilator support in patients with acute lung injury. Am J Respir Crit Care Med 2001;164(1):43-49.

41. Varpula T, Valta P, Niemi R, Takkunen O, Hynynen M, Pettila V. Airway pressure release ventilation as a primary ventilator mode in acute respiratory distress syndrome. Acta Anaesthesiol Scand 2004; 48(6):722-731.

42. Fan E, Stewart T. New Modalities of mechanical ventilation: highfrequency oscillatory ventilation and airway pressure release ventilation. Clin Chest Med 2006;27(4):615-625.

43. Chan K, Stewart T. Clinical use of high-frequency oscillatory ventilation in adult patients with acute respiratory distress syndrome. Crit Care Med 2005;33(3 Suppl):S170-S174.

44. Stawicki S, Goyal M, Sarani B. High-frequency oscillatory ventilation (HFOV) and airway pressure release ventilation (APRV): a practical guide. J Intensive Care Med 2009;24(4):215-229.

45. van Heerde M, Roubik K, Kopelent V, Plötz F, Markhorst D. Unloading work of breathing during high-frequency oscillatory ventilation: a bench study. Crit Care 2006;10(4):R103. DOI: 10.1186/ cc4968.

46. Fessler H, Derdak S, Ferguson N, Hager D, Kacmarek R, Thompson $\mathrm{T}$, et al. A protocol for high-frequency oscillatory ventilation in adults: results from a roundtable discussion. Crit Care Med 2007; 35(7):1649-1654.

47. Graciano A. Feasibility of asynchronous independent lung high-frequency oscillatory ventilation in the management of acute hypoxemic respiratory failure: a case report. Crit Care Med 2000;28(8): 3075-3077.

48. Mehta S, Lapinsky S, Hallet D, Merker D, Groll R, Cooper A, et al. A prospective trial of high frequency oscillatory ventilation in adults with acute respiratory distress syndrome. Crit Care Med 2001;29(7): 1360-1369.

49. Eastman A, Holland D, Higgins J, Smith B, Delagarza J, Olson C, et al. High-frequency percussive ventilation improves oxygenation in trauma patients with acute respiratory distress syndrome: a retrospective review. Am J Surg 2006;192(2):191-195.

50. Paulsen S, Killyon G, Barillo D. High-frequency percussive ventilation as a salvage modality in adult respiratory distress syndrome: a preliminary study. Am Surg 2002;68(10):854-856.

51. Derdak S, Mehta S, Steward T, Smith T, Rogers M, Buchman T, et al. High-frequency oscillatory ventilation for acute respiratory distress syndrome in adults: a randomized controlled trial. Am J Respir Crit Care Med 2002;166(6):801-808.

52. Bollen C, van Well G, Sherry T, Beale R, Shah S, Findlay G, et al. High frequency oscillatory ventilation compared with conventional mechanical ventilation in adult respiratory distress syndrome: a randomized controlled trial. Crit Care 2005;9(4):R430-439.

53. Sud S, Sud M, Friedrich J, Meade M, Ferguson N, Wunsch H, Adhikari N. High frequency oscillation in patients with acute lung injury and acute respiratory distress syndrome (ARDS): systematic review and meta-analysis. BMJ 2010;340:c2327. DOI: 10.1136/ bmj.c2327.

54. Ferguson ND, Meade MO; Canadian Critical Care Trials Group; Canadian Institutes of Health Research (CIHR). The Oscillation for ARDS Treated Early (OSCILLATE) trial pilot study. http://clinicaltrials.gov/ct2/show/NCT00474656. Accessed August 9, 2011. 


\section{APPROACHES to ReFRactory HypoXemia IN ARDS}

55. Piehl M, Brown R. Use of extreme position changes in acute respiratory failure. Crit Care Med 1976;4(1):13-14.

56. Chatte G, Sab J, Dubois J, Sirodot M, Gaussorgues P, Robert D. Prone position in mechanically ventilated patients with severe acute respiratory failure. Am J Respir Crit Care Med 1997;155(2):473478.

57. Gattinoni L, Tognoni G, Pesenti A, Taccone P, Mascheroni D, Labarta V, et al; Prone-Supine Study Group. Effect of prone positioning on the survival of patients with acute respiratory failure. N Engl J Med 2001;345(8):568-573.

58. Guerin C, Gaillard S, Lemasson S, Ayzac L, Girard R, Beurer P, et al. Effects of systematic prone positioning in hypoxemic acute respiratory failure: a randomized controlled trial. JAMA 2004;292(19): 2379-2387.

59. Mancebo J, Fernandez R, Blanch L, Rialp G, Gordo F, Ferrer M, et al. A multicenter trial of prolonged prone ventilation in severe acute respiratory distress syndrome. Am J Respir Crit Care Med 2006; 173(11):1233-1239.

60. Taccone P, Pesenti A, Latini R, Polli F, Vagginelli F, Mietto C, et al; Prone-Supine II Study Group. Prone positioning in patients with moderate and severe acute respiratory distress syndrome: a randomized controlled trial. JAMA 2009;302(18):1977-1984.

61. Sud S, Sud M, Friedrich J, Adhikari N. Effect of mechanical ventilation in the prone position on clinical outcomes in patients with acute hypoxemic respiratory failure: a systematic review and metaanalysis. CMAJ 2008;178(9):1153-1161.

62. Alsaghir A, Martin C. Effect of prone positioning in patients with acute respiratory distress syndrome: a meta-analysis. Crit Care Med 2008;36(2):603-609.

63. Abroug F, Ouanes-Besbes L, Elatrous S, Brochard L. The effect of prone positioning in acute respiratory distress syndrome or acute lung injury: a meta-analysis. Areas of uncertainty and recommendations for research. Intensive Care Med 2008;34(6):1002-1011.

64. Tiruvoipati R, Bangash M, Manktelow B, Peek G. Efficacy of prone ventilation in adult patients with acute respiratory failure: a metaanalysis. J Crit Care 2008;23(1):101-110.

65. Sud S, Friedrich J, Taccone P, Polli F, Adhikari N, Latini R, et al. Prone ventilation reduces mortality in patients with acute respiratory failure and severe hypoxemia: systematic review and meta-analysis. Intensive Care Med 2010;36(4):585-599.

66. Tomashefski J, Davies P, Boggis C, Greene R, Zapol W, Reid L. The pulmonary vascular lesions of the adult respiratory distress syndrome. Am J Pathol 1983;112(1):112-126.

67. Zapol W, Snider M. Pulmonary hypertension in severe acute respiratory failure. N Engl J Med 1977;296(9):476-480.

68. Adhikari NK, Burns KE, Friedrich JO, Granton JT, Cook DJ, Meade MO. Effect of nitric oxide on oxygenation and mortality in acute lung injury: systematic review and meta-analysis. BMJ 2007; 334(7597):779. DOI: 10.1136/bmj.39139.716794.55.

69. Raoof S, Goulet K, Esan A, Hess DR, Sessler CN. Severe hypoxemic respiratory failure: part 2: non-ventilatory strategies. Chest 2010; 137(6): 1437-1448.

70. Taylor R, Zimmerman J, Dellinger R, Straube R, Criner G, Davis Jr $\mathrm{K}$, et al; Inhaled Nitric Oxide in ARDS Study Group. Low-dose inhaled nitric oxide in patients with acute lung injury: a randomized controlled trial. JAMA 2004;291(13):1603-1609.

71. Michael J, Barton R, Saffle J, Mone M, Markewitz B, Hillier K, et al. Inhaled nitric oxide versus conventional therapy: effect on oxygenation in ARDS. Am J Respir Crit Care Med 1998;157(5 pt 1): 1372-1380.

72. Dellinger R, Zimmerman J, Taylor R Straube R, Hauser D, Criner G, et al. Effects of inhaled nitric oxide in patients with acute respiratory distress syndrome: results of a randomized phase II trial. Inhaled
Nitric Oxide in ARDS Study Group. Crit Care Med 1998;26(1):1523.

73. Troncy E, Collet J, Shapiro S, Guimond J-G, Blair L, Ducruet T, et al. Inhaled nitric oxide in acute respiratory distress syndrome: a pilot randomized controlled study. Am J Respir Crit Care Med 1998; $157(5$ pt 1):1483-1488

74. Lundin S, Mang H, Smithies M, Stenqvist O, Frostell C; The European Study Group of Inhaled Nitric Oxide. Inhalation of nitric oxide in acute lung injury: results of a European multicenter study. Intensive Care Med 1999;25(9):911-919.

75. Griffiths M, Evans T. Inhaled nitric oxide therapy in adults. N Engl J Med 2005;353(25):2683-2695.

76. Sidebotham D, McGeorge A, McGuinness S, Edwards M, Wilcox T, Beca J. Extracorporeal membrane oxygenation for treating severe cardiac and respiratory failure in adults: part 2: technical considerations. J Cardiothorac Vasc Anesthes 2010;24(1):164-172.

77. Zapol W, Snider M, Hill J, Fallat R, Bartlett R, Edmunds L, et al. Extracorporeal membrane oxygenation in severe acute respiratory failure. A randomized prospective study. JAMA 1979;242(20):21932196.

78. Morris A, Wallace C, Menlove R, Clemmer T, Orme J Jr., Weaver $\mathrm{L}$, et al. Randomized clinical trial of pressure-controlled inverse ratio ventilation and extracorporeal $\mathrm{CO}_{2}$ removal for adult respiratory distress syndrome. Am J Respir Crit Care Med 1994;149(2):295305

79. Bartlett R, Roloff D, Custer J, Younger J, Hirschl R. Extracorporeal life support: the University of Michigan experience. JAMA 2000; 283(7):904-908.

80. Nehra D, Goldstein A, Doody D, Ryan D, Chang Y, Masiakos P. Extracorporeal membrane oxygenation for non-neonatal acute respiratory failure: the Massachusetts General Hospital experience from 1990 to 2008. Arch Surg 2009;144(5):427-432.

81. Peek G, Mugford M, Tiruvoipati R, Wilson A, Allen E, Thalanany $\mathrm{M}$, et al. Efficacy and economic assessment of contentional ventilatory support versus extracorporeal membrane oxygenation for severe adult respiratory failure (CESAR): a multicenter randomized controlled trial. Lancet 2009;374(9698):1351-1363.

82. Australia and New Zealand Extracorporeal Membrane Oxygenation (ANZ ECMO) Influenza Investigators; Davies A, Jones D, Bailey M, Beca J, Bellomo R, Blackwell N, et al. Extracorporeal membrane oxygenation for 2009 influenza A (H1N1) acute respiratory distress syndrome. JAMA 2009;302(17):1888-1895.

83. Betit P. Extracorporeal membrane oxygenation: quo vadis? Respir Care 2009;54(7):948-957.

84. Novalung. iLA membrane ventilator. http://www.novalung.com/en/ ila. Accessed August 9, 2011.

85. Meyer A, Strüber M, Fischer S. Advances in extracorporeal ventilation. Anesthesiology Clin 2008;26(2):381-391.

86. Lobaz S, Carey M. Rescue of acute refractory hypercapnia and acidosis secondary to life-threatening asthma with extracorporeal carbon dioxide removal (ECCO2R). JICS 2011;12(2):140-142.

87. Fischer S, Simon A, Welte T, Hoeper M, Meyer A, Tessman R, et al. Bridge to lung transplantation with the novel pumpless interventional lung assist device Novalung. J Thorac Cardiovasc Surg 2008; 131(3):719-723.

88. Zimmermann M, Bein T, Arlt M, Phillip A, Rupprecht L, Mueller T, et al. Pumpless extracorporeal interventional lung assist in patients with acute respiratory distress syndrome: a prospective pilot study. Crit Care 2009;13(1):R10. DOI: 10.1186/cc7703.

89. Briel M, Meade M, Mercat A, Brower R, Talmor D, Walter S, et al. Higher vs lower positive end-expiratory pressure in patients with acute lung injury and acute respiratory distress syndrome. JAMA 2010;303(9):865-873. 